\title{
A REALIZAÇÃO DA FLEXIBILIZAÇÃO TRABALHISTA PELAS INSTITUIÇÕES TRABALHISTAS EM GERAL E EM PARTICULAR PELA AUDITORIA-FISCAL DO TRABALHO
}

\section{LA RÉALISATION DE LA FLEXIBILISATION DU TRAVAIL PAR LES INSTITUTIONS DU TRAVAIL EN GÉNÉRAL ET NOTAMMENT PAR L'INSPECTION DU TRAVAIL}

\begin{abstract}
${ }^{1}$ Alessandro Severino Valler Zenni
${ }^{2}$ Paulo Ricardo Vijande Pedrozo

\section{RESUMO}

O objetivo deste trabalho é demonstrar a existência de instituições trabalhistas que editam e /ou aplicam a legislação e o direito do trabalho no Brasil, em especial a Auditoria-Fiscal do Trabalho, que detêm protagonismo na realização da flexibilização trabalhista no país. É objetivo deste trabalho também estudar a relação entre o direito do trabalho e os direitos da personalidade, e em que medida se justificaria a flexibilização trabalhista protagonizada com o novel projeto sobre a terceirização. Este trabalho analisa a legitimidade do Projeto de Lei n. 4.330/2004, que dispõe sobre os contratos de terceirização e as relações de trabalho deles decorrentes que visa instituir a possibilidade de terceirização generalizada, seja das atividades-meio, seja das atividades-fim das empresas, sob um ponto de vista histórico e filosófico, precipuamente sob a ótica do personalismo ético. A fiscalização do pleno emprego e da justiça social é tarefa que incumbe ao Estado, a partir do projeto constitucional, derramando-se a órgãos afeitos ao Executivo e Judiciário, no plano da eficácia concreta da Constituição, ao mesmo instante em que o legislador sacramenta os direitos sociais no plano normativo, fortalecendo o direito do trabalho e a dignidade da pessoa humana.

Palavras-chave: Direito do trabalho, Dignidade humana, Terceirização, Fiscalização laboral

\section{RÉSUMÉ}

L'objectif de cette étude est de démontrer l'existence d'institutions du travail et d'édition ou d'appliquer la loi et le droit du travail au Brésil, en particulier l'inspection du travail, qui détiennent rôle moteur dans la réalisation de la flexibilité du travail dans le pays. L'objectif de cette travaille est aussi d'étudier la relation entre le droit du travail et aux droits de la personnalité, et la mesure de justifier la flexibilité du travail presentée avec le projet novateur sur la délocalisation. Cet article analyse la légitimité du projet de loi no. 4330/2004, qui prévoit les contrats de délocalisation et leurs relations de travail qui en découlent, qui vise à établir la possibilité de sous-traitance généralisée, si les activités-moyens, les entreprises activités finales d'un point de vue historique et philosophique, principalement du point de vue du personnalisme éthique. L'inspection du plein emploi et la justice sociale est une tâche qui incombe à l'État, à partir du projet constitutionnel, débordant les organismes habitués à l' exécutif et le judiciaire, sur l'efficacité réelle du plan de la Constituition au même instant le législateur consacre le droits sociaux en termes législatifs, le droit du travail et le renforcement de la dignité de la personne humaine.

Mots-clés: Droit du travail, La dignité humaine, Sous-traitance, L’inspection du travail

\footnotetext{
${ }^{1}$ Doutor em Filosofia do Direito pela Pontifícia Universidade Católica de São Paulo - PUC/SP, São Paulo (Brasil). Professor do Centro Universitário de Maringá - UNICESUMAR, Paraná (Brasil). E-mail: asvzenni@ hotmail.com

${ }^{2}$ Mestre em Direitos da Personalidade pelo Centro Universitário de Maringá - UNICESUMAR, Paraná (Brasil). Professor de Direito do Trabalho da Faculdade Cidade Verde - FCV, Paraná (Brasil). E-mail: paulo.pedrozo.unicesumar@gmail.com
} 


\section{INTRODUÇÃO}

O presente artigo foi elaborado para participação no XXIV Congresso Nacional do Conselho Nacional de Pesquisa e Pós-Graduação em Direito (CONPEDI).

Os métodos de pesquisa utilizados foram o indutivo e o dedutivo.

O indutivo, porque a pesquisa partiu da constatação de um fato social, o protagonismo de instituições trabalhistas brasileiras em geral, e em particular pela Auditoria- Fiscal do Trabalho. O método dedutivo foi utilizado porque o fato social social mencionado consiste, ele mesmo, em aplicação de normas gerais trabalhistas a espécies fáticas trabalhistas, ou seja, aplicação de normas gerais a fatos particulares. Mesmo quanto à criação da legislação trabalhista, consiste na aplicação de normas e princípios constitucionais e jurídicos.

Foi realizada pesquisa normativa, doutrinária e jurisprudencial a respeito do tema.

Para a elaboração do presente artigo utilizar-se-á como base trabalhos apresentados como tarefas finais e em seminários de disciplinas do Programa de Mestrado em Direito do Unicesumar em Maringá/PR.

Será utilizado como base, também, artigo elaborado para participação no livro comemorativo dos 10 anos do Programa de Mestrado em Direito do Unicesumar, intitulado "A Dignidade da Pessoa do Trabalhador e a Precarização do Trabalho Pela Via da Terceirização".

Tais trabalhos têm, cada qual, características de originalidade, já que realizados com a utilização de estudos pertinentes a cada uma das disciplinas e objetivos mencionados. Em comum, todos têm relação com a preparação da dissertação que consistirá no trabalho final a ser apresentado no Programa de Mestrado em Direito do Unicesumar.

Conforme procurar-se-á demonstrar no presente artigo, as instituições trabalhistas existentes no país, em geral, e em particular a Auditoria-Fiscal do Trabalho, têm, cada qual, importância e atribuições específicas na realização da flexibilização trabalhista que tem sido admitida pela doutrina e pela jurisprudência, bem como também pela legislação, inclusive projetada.

\section{DESENVOLVIMENTO}

\section{A DIGNIDADE DA PESSOA HUMANA NA RELAÇÃO DE EMPREGO}

Inicialmente há de se destacar que a dignidade da pessoa humana corresponde a valor de natureza ética, de cunho essencialmente filosófico, e que se implica diretamente com o sentido à vida, requestando exame profundo na definição. 
Se o ser humano é essencialmente corpo e inteligência, já definido como tal pela metafísica grega (ARISTÓTELES, 1982, p. 295, 1102a), a formulação do conceito de pessoa parte em Tomás de Aquino a do ser do humano em relação de conformidade com seu dever ser (AQUINO, 2001, p. 748). O devir corresponde aos valores que o ser do humano naturalmente há de cumprir para dar sentido à vida, o desenvolvimento de suas potencialidades, desde as paixões corporais às faculdades da alma, em uma linha de verticalidade que o faz transcender no ser, um ser a fazer, cuja ordem e fim se há de observar, inclusive no ambiente laboral (ZENNI, 2008, p. 67).

Essa ascensão valorativa que parte do ego e responde aos prazeres materiais, máxime o útil, que se traduz na afeição aos bens que geram satisfação provisória, o puro eu em demasia, tem como intermediário o vital indispensável ao existir, e amplia-se nos bens da alma, a ética, a beleza e a verdade, faz-se pela liberdade como motor. Ocorre que nem todos conseguem palmilhar a vereda sponte sua, exigindo, portanto, a suplência de grupos, entre eles a empresa, os sindicatos, e o próprio Estado, dando-lhes condições de igualdade para tornarem-se pessoas dignas.

Vê-se, portanto, que a concepção de pessoa, sempre relação com o alter, e com os sentidos e os valores, reivindica a definição de justiça, a garantia de fruição de bens consoante o mérito, e ao Direito impõe-se, como instrumento de realização do justo e tradução natural da metafisica humana, a tarefa de dignificar pessoas, inclusive os laboristas no mundo da faina (ZENNI, 2008, p. 69).

Não é por outra razão que, alinhavando os valores político-jurídicos fundamentais da República, a Constituição exige a compatibilização entre valor social do trabalho e a livre iniciativa, sugerindo, no plano dos direitos econômicos o respeito à dignidade do trabalhador, à plenitude do emprego e o respeito ao meio ambiente, incluindo o do trabalho.

Assim, o exame de qualquer norma no plano juslaboralista há de ser contrastada com essa plêiade de valores, supracitada, à luz do princípio formal da interpretação conforme à Constituição (ZENNI, 2008, p. 78).

O valor social do trabalho indica que a garantia de alimentos a satisfazer as mínimas condições de existência se colhe do labor, tornando os contratos de emprego os mais sociais entre os pactos firmados, sugerindo-se uma vontade social de suas cláusulas que se sobrepõem às vontades individuais e transcendem mesmo as intenções das partes. Sabe-se que as maiores tensões históricas tiveram origem na escassez das ofertas de labuta, gerando-se um 
caos social que, em certo momento da experiência humana eclodiu na própria gênese do direito laboral, inaugurando-se, mesmo, um novel modelo de Estado e de Direito, de cariz interventivo e reconhecedor de hipossuficiências grupais a recrutar prestações positivas. ${ }^{1}$

Contemporaneamente a Constituição galga o trabalho a direito social, e a relação de emprego conta com garantias mínimas no bojo da Carta, tratando-se de direitos fundamentais reconhecidos pela Suprema Corte como cláusulas pétreas insuscetíveis, mesmo, de reforma constitucional (BELTRAMELLI NETO, 2008, p. 70 e seguintes).

Outrossim, ainda delineando os valores incorporados à Constituição, não se pode relegar a limitação taxativa à livre iniciativa, prescrita no art. 170, VI, no sentido de que o meio ambiente impõe respeito daquele que se propõe ao lucro, considerando-se como subitem, o meio ambiente do trabalho, à luz do que dispõe sistemicamente a compreensão dos dispostos nos artigos 225 e 200, VIII, da CF.

Portanto, qualquer relação trabalhista que descurar de tais bens jurídicos protegidos constitucionalmente, padecerá de inconstitucionalidade material.

\footnotetext{
${ }^{1}$ Sabe-se que até o advento da Revolução Industrial, o labor como objeto de contrato tinha suas cláusulas fixadas pelos sujeitos contratantes, ao sabor das suas vontades, vislumbrando-se a adesão do operário a crivo burguês, até que a escorchante situação de labuta redundou em vera revolução trabalhista, dando-se ensejo ao Manifesto Comunista e, também, à Encíclica Rerum Novarum, no que, de comum, deliberaram sobre a dignidade do laborista como exigência do Direito, semeando as bases do protecionismo e do próprio Direito do Trabalho.
} 


\section{O PRINCÍPIO DO PLENO EMPREGO COMO LIMITE À LIVRE INICIATIVA}

A forma de contrato de trabalho que goza de proteção jurídica, por excelência, diz com o pacto empregatício, à medida que a subordinação lhe dá tônica, submetendo o laborista não só a estruturação diretiva do empregador, senão às suas ordens diretas, supondo-se, por conta disso, uma espécie de presunção de coação no agir do trabalhador que, por si só, está a justificar um regime de tutela estatal.

E também porque o empregado mantém dependência estrutural e econômica com o empregador, ainda que lhe seja reconhecido o direito de resistência, às ordens anticontratuais e/ou indignas, está ínsita, pelo próprio elemento subordinativo, uma certa restrição à autonomia do sujeito laborista no ambiente de trabalho.

No mais, o sujeito empregado, classificado pelo art. $3^{\circ}$, da CLT, pela pessoalidade, habitualidade, onerosidade e subordinação, mesmo adicto às diretrizes pessoais e ou estruturais do empregador há de ser reputado pessoa em sua concepção, havendo de dignificar-se, também, na esfera do trabalho.

Exatamente porque o empregador dispõe da capacidade organizacional e irradia suas diretrizes aos laboristas contratados, sempre no anseio do lucro, o respeito à pessoa do empregado para evitar a sua alienação e "mecanização" na sistemática do regime do capital. Sobre essa preocupação já anunciava Leão XIII, o compromisso social assumido pela humanidade em pleno regime de livre iniciativa invocando a função social do contrato (ZENNI \& SILVA, 2015). ${ }^{2}$

Em nosso sentir a plenitude da empregabilidade recomendada pela Constituição como linde à livre iniciativa implica em que o empregador, a quem é legítimo o lucro por força principiológica fundamental (LOCKE, 2001, p. 98) ${ }^{3}$, em nome da função social da propriedade, que se traduz como compromisso ético igualmente cardeal, ex vi do Texto Magno (art. $5^{\circ}$,

\footnotetext{
${ }^{2}$ A doutrina social da Igreja, irradiadora das raízes do direito do trabalho, sempre objetou a pura ideia de socialização plena da propriedade privada, mas advertia ser indispensável, no âmbito da livre iniciativa, que, por questão ética, e à vista de o todo preexistir às partes, que os contratos de trabalho reconhecessem o trabalhador como um sujeito e não como objeto, buscando emancipá-lo como pessoa, ao mesmo tempo em que excogitou de sua participação nos lucros, como técnica de justiça na plano da mais valia. Já se defendeu que uma das formas de construção da mais valia social está na implantação dos planos de participação em lucros ou resultados como distribuição ética dos bens e forma justa de partilha no capital e trabalho.

${ }^{3}$ Deve-se a Locke a empreitada primeva de afirmar a livre iniciativa como direito e garantia pública posta como reconhecimento e, ao mesmo tempo, limite imposto contra o Estado nos albores do liberalismo. De acordo com o filósofo o trabalho livre conduz à aquisição da propriedade privada e, por consequência, à sua utilização e aproveitamento, dando gênese ao lucro como direito instituído.
} 
XXIII), está vedada a precarização no campo das relações contratuais envolvendo o capital e o trabalho.

E mesmo que a CLT tenha reduzido a perspectiva do contrato de emprego ao "plano meramente patrimonial", nos dizeres de MALLET (2007, p. 8), ressalta o juslaboralista mostrarse injustificada a proposta do estatuto trabalhista, a fortiori por ser o laborista uma pessoa com direito à dignidade humana, ou seja, a leitura do vínculo de emprego passa pela repersonalização no âmbito da Constituição Federal e à luz do princípio basilar da dignidade da pessoa.

ZENNI (2008, p. 60), por sua vez, demonstra a existência de doutrina de que a dignidade da pessoa humana ressignificou os princípios de direito do trabalho, dando-lhes dimensão personalíssima que, até o advento da Constituição em 1988, eram diretivas, sobretudo, de cunho patrimonial.

Inegável que a Consolidação já trazia preocupação com a preservação da dignidade do trabalhador, conquanto fosse esse o valor a lançar luzes na edificação do direito do trabalho em seu nascedouro, bastando leitura da Encíclica Rerum Novarum. No escopo de proteger o empregado como pessoa, a CLT, alhures já tratava de priorizar um ambiente de trabalho hígido, saudável e protegido de todos os agentes de risco, impondo ao empregador cuidados com a preservação da saúde, segurança e medicina no trabalho como, ainda, instituindo um direito administrativo do trabalho, cujo cariz é de autorizar fiscalização e imposição de sanções por agentes do Estado (Ministério do Trabalho e Emprego), chegando às imprecações máximas de interditar a atividade econômica quando o espaço da labuta gera risco à vida e ou integridade física aos laboristas.

Enfim, desde 1943, uma preocupação cardinal se enfeixa na CLT, superando a visão patrimonialista dos vínculos contratuais até então vigorantes, vertendo normas de proteção aos direitos de personalidade do trabalho, inclusive com a intervenção direta do Estado, via Ministério do Trabalho e Emprego, cujas linhas evidenciam, a um só tempo, a novel postura do Estado Democrático reconhecida a partir do direito do trabalho, de intervenção na esfera privada, dotando o grupo laborista, de bens jurídicos, em razão de sua hipossuficiência. ${ }^{4}$

\footnotetext{
4 O Capítulo da CLT "Da Segurança e da Medicina no Trabalho" tem hoje a denominação científica de "Segurança e Saúde do Trabalho", já que contém regras referentes à saúde do trabalhador que não são estritamente de medicina do trabalho, como, por exemplo, as referentes à ergonomia do trabalho, previstas na Norma Regulamentadora (NR) 17, do Ministério do Trabalho e Emprego (MTE).
} 
A propósito, todas as Normas Regulamentadoras (NRs) de Segurança e Saúde do Trabalho, editadas pelo Ministro do Trabalho e Emprego por força do art. 200 da CLT (dentre as quais se encontram as de n. 15 e 16, referentes à insalubridade e à periculosidade dos locais de trabalho) também tratam de direitos da personalidade dos trabalhadores, uma vez que têm como objetivo a proteção da vida e da saúde da pessoa humana (BRASIL, 2014).

Desafia estudo mais aprofundado à legislação quando prevê a existência de adicionais salariais ligados à segurança e à saúde do trabalho, pela labuta em atividades designadas como de risco, fixadas na Constituição como àquelas que projetam o laborista em contato com agentes insalubres, ambientes periculosos, como, ainda, penosos, a despeito de o STF já se ter manifestado pela natureza não auto exequível da norma (art. $7^{\circ}, \mathrm{XXIII}$, da $\mathrm{CF}$ ), padecendo as atividades penosas da falta de um acréscimo legal ainda por ser instituído (BRASIL, 2015).

Com efeito, se a Constituição se propõe a blindar o sujeito empregado de toda "coisificação", dotando-lhe de uma condição pessoal, exigindo que haja compromisso com preservação do meio ambiente, inclusive o do trabalho, em leitura sistêmica dos arts. $225 \mathrm{e}$ 198, VIII, da CF, além de cercear o escopo do lucro (inciso VI, do art. 170), a geração dos adicionais no inciso XXIII, do art. $7^{\circ}$, haveria de ser entendida como uma espécie de desestímulo a captação da vantagem econômica na exploração do risco à saúde e vida dos laboristas (ZENNI \& OLIVEIRA, 2009, p. 88). ${ }^{5}$

Todavia, com fixação de adicionais em níveis parcos, e o reconhecimento da natureza salarial da verba e reflexos remuneratórios, torna-se, ao contrário, um atrativo ao laborista o exercício da labuta em ambiente de risco, sem embargo de que o próprio empregador, fazendo uma planilha de custo e risco, no engajamento das regras de direito, prefere manter a precariedade do ambiente de trabalho mediante quitação dos adicionais respectivos a engendrar investimentos custosos para evitar a periclitação da vida ou da saúde dos trabalhadores, subvertendo a noção de pessoa, reduzindo-a ao critério utilitarista presente na cultura pós-moderna ${ }^{6}$.

\footnotetext{
${ }^{5}$ Há quem faça a defesa das normas inconstitucionais entronizadas na Constituição, de que seria exemplo essa do inciso XXIII, do art. $7^{\circ}$, ao criar os adicionais às atividades de risco, quando a preocupação central do direito constitucional do trabalho é de preservar a dignidade da pessoa humana.

${ }^{6}$ ZENNI, Alessandro Severino Valler e FILHO ANDREATA, Daniel Ricardo. O Direito na Perspectiva da Dignidade Humana. Porto Alegre: Sérgio Antonio Fabris, 2010.
} 
De todo modo o meio ambiente do trabalho tem sido aplacado pela doutrina juslaboralista como tema de vanguarda e das mais relevantes preocupações, sobretudo por inteirar-se da vida e integridade físico-psíquica dos trabalhadores.

Leda Maria Messias da SILVA (2014), em passagem também citada no livro que publicou em conjunto com Marice Taques Pereira (SILVA \& PEREIRA, 2013, p. 25), assim o delimita:

o meio ambiente do trabalho está contido no meio ambiente geral, o qual, na esfera trabalhista, e, especialmente, do contrato de trabalho deve-se compreender como meio ambiente do trabalho não só o local onde o trabalhador presta o seu serviço, mas também como parte do meio ambiente do trabalho, todos os fatores internos ou externos que possam interagir com o trabalho e influenciar de alguma forma esse meio ambiente, contribuindo para o seu equilíbrio ou desequilíbrio.

A decência no meio ambiente laboral exorta o empregador à prevenção dos riscos da atividade e fomenta a prática fiscalizatória dos órgãos estatais, mormente o Ministério do Trabalho e Emprego, sem embargo da atividade de custódia do Ministério Público do Trabalho.

Raimundo Simão Melo (2013, p. 66) comenta sobre a prevenção dos riscos no meio ambiente de trabalho como parte do "princípio constitucional da dignidade humana e os valores sociais do trabalho", aludindo que "embora capitalista, a ordem econômica dá prioridade aos valores do trabalho humano sobre todos os demais valores da economia de mercado".

A seguir (2013, p. 68), implementa:

[...] há degradação das condições de trabalho no Brasil e em países chamados emergentes, submetidos francamente às regras internacionais, com aumento dos acidentes e doenças do trabalho. Diante disso, o valor ou princípio da dignidade da pessoa humana deve ter sentido de normatividade e cogência e não de meras cláusulas "retóricas" ou de estilo ou de manifestações de bons propósitos, daí por que é preciso dar tratamento adequado aos instrumentos de efetivação dos direitos que poderão realmente garantir a dignidade do trabalhador e o valor verdadeiramente social do trabalho, como estabelece nossa Carta Maior.

De toda sorte um constructo de sustentabilidade no meio ambiente do trabalho ancora o ideário da mais valia social, como alinhavar de interesses. E no direito do trabalho a vala para evitar a implantação arbitrária do socialismo em que os bens são, pura e simplesmente repartidos, sem levar em consideração o mérito na distribuição do justo e o prestígio à autonomia (ZENNI \& OLIVEIRA, 2009, p. 72). 
A tal respeito, a lição de Segadas Vianna (in: SÜSSEKIND, MARANHÃO, VIANNA, \& TEIXEIRA, 2003, p. 39), referindo-se ao final do século XIX, e o surgimento do direito do trabalho pelas orientações da Encíclica Rerum Novarum:

[...] o Papa Leão XIII publica a Encíclica "Rerum Novarum" e proclama a necessidade da união entre as classes do capital e do trabalho, que têm "imperiosa necessidade uma da outra; não pode haver capital sem trabalho nem trabalho sem capital. A concorrência traz consigo a ordem e beleza; ao contrário, de um conflito perpétuo, não podem resultar senão confusão e lutas selvagens".

A palavra do Sumo Sacerdote ecoou e impressionou o mundo cristão, incentivando o interesse dos governantes pelas classes trabalhadoras, dando força para sua intervenção, cada vez mais marcante, nos direitos individuais em benefício dos interesses coletivos.

No tempo presente, o pontificado de FRANCISCO (2014) trouxe a exortação apostólica Evangelii Gaudium, lendo-se o que segue:

189. A solidariedade é uma reacção espontânea de quem reconhece a função social da propriedade e o destino universal dos bens como realidades anteriores à propriedade privada. A posse privada dos bens justifica-se para cuidar deles e aumentá-los de modo a servirem melhor o bem comum, pelo que a solidariedade deve ser vivida como a decisão de devolver ao pobre o que lhe corresponde. Estas convicções e práticas de solidariedade, quando se fazem carne, abrem caminho a outras transformações estruturais e tornam- nas possíveis. Uma mudança nas estruturas, sem se gerar novas convicções e atitudes, fará com que essas mesmas estruturas, mais cedo ou mais tarde, se tornem corruptas, pesadas e ineficazes.

O início de tal passagem é lembrada por PINTO (2014, p. 67), relacionando-a ao "legislador, o magistrado, o doutrinador que fizeram da propriedade privada um dogma absoluto a serviço do proprietário e agora lêem o Papa".

Posto isso não paira dúvida de que a livre iniciativa há de consorciar a expectativa do lucro à realização da pessoa humana no âmago da exploração da atividade econômica, máxime pela função social da propriedade privada, imperativo erigido na Constituição no art. 170, III, da CF.

\section{PESSOA E PERSONALIDADE HUMANA}

A preocupação central do artigo constitucional antes mencionado está na construção da personalidade no mundo do trabalho diante do capitalismo selvagem que tem assolado a humanidade presentemente. 
Também se fez assentar que a origem do termo pessoa é de cunho religioso, pautada na doutrina da Igreja, especialmente no Concílio de Nicéia, vindo a ser tema de grande elucubração na Suma Teológica do doutor angélico (AQUINO, 2001). Em poucas ocasiões na história da humanidade o princípio da dignidade da pessoa fez ecoar seu conteúdo essencial, ressalvando que, inicialmente, coube ao próprio tomismo nutrir o direito com igualdade entre pessoas, a partir da exigência de dignidade entre todos os seres irmanados no Criador.

E num segundo instante, já em plena modernidade de segunda fase, coube ao Papa LEÃO XIII (2015) recorrer ao princípio da dignidade humana para tutelar a classe operária, tão massacrada pela obsessão burguesa ao lucro, como se lê da Encíclica Rerum Novarum:

Quem tiver na sua frente o modelo divino, compreenderá mais facilmente o que Nós vamos dizer: que a verdadeira dignidade do homem e a sua excelência reside nos seus costumes, isto é, na sua virtude; que a virtude é o património comum dos mortais, ao alcance de todos, dos pequenos e dos grandes, dos pobres e dos ricos; só a virtude e os méritos, seja qual for a pessoa em quem se encontrem, obterão a recompensa da eterna felicidade. Mais ainda: é para as classes desafortunadas que o coração de Deus parece inclinar-se mais. Jesus Cristo chama aos pobres bem-aventurados (20): convida com amor a virem a Ele, a fim de consolar a todos os que sofrem e que choram (21); abraça com caridade mais terna os pequenos e os oprimidos. Estas doutrinas foram, sem dúvida alguma, feitas para humilhar a alma altiva do rico e torná-lo mais condescendente, para reanimar a coragem daqueles que sofrem e inspirar-lhes resignação. Com elas se acharia diminuído um abismo causado pelo orgulho, e se obteria sem dificuldade que as duas classes se dessem as mãos e as vontades se unissem na mesma amizade.

Nesse instante, aliás, recorrendo-se ao principio da isonomia material e à exigência de tratamento díspar à medida das desigualdades reais que circunscreviam a realidade econômica e técnica nas relações de trabalho, surge o Direito do trabalho como remédio aos males do liberalismo de da postura pálida do Estado na preservação da dignidade operária.

GONÇALVES (2008, p. 64) formula um conceito de pessoa: "é aquele ente que, em virtude da especial intensidade do seu acto de ser, autopossui a sua própria realidade ontológica, em abertura relacional constitutiva e dimensão relacional unitiva".

Outrossim, personalidade é "o conjunto das qualidades e relações que determinam a pessoa em si mesma e em função da participação na ordem do ser, de forma única e singular" (idem, p. 68)..

Tais conceitos descrevem a realidade relacional da pessoa humana e da personalidade que ela detém. Isso significa dizer que tal realidade se concretiza na vida em sociedade, nas relações que os seres humanos mantêm uns com os outros, cada um com a sua participação individual, e construindo, todos, uma realidade social unitária. 
Vistos tais conceitos de pessoa e de personalidade, forçosamente há de ser postular garantias fundamentais sem as quais a periclitação do ser detrai a condição humana do sujeito. No entorno da pessoa gravitam os direitos fundamentais, inclusive os de natureza social, como de matriz trabalhista.

Não é demais destacar que os direitos humanos, outrora postularam-se bens de natureza ético-cristã, sucessivamente a Revolução Francesa os torna conquistas políticas, imprimindo-lhes efeitos vinculantes pela via da positivação jurídica até serem concebidos como direitos fundamentais a requestarem máxima efetividade.

Registre-se, por oportuno, que a plenitude do emprego, como opróbio à selvageria do capitalismo, alçado a bem jurídico na Constituição, como já se aludiu, esparge imediatamente eficácia, tanto no âmbito positivo, no sentido de concebê-lo direito subjetivo a ser advogado judicialmente, como, ainda, no sentido negativo, empecendo uma interpretação a contrario ao baluarte consagrado ao mesmo tempo em que reprova energicamente legislação infraconstitucional da precarização do pacto empregatício em direitos, a par de conter o retrocesso social (BARCELOS, 2008). ${ }^{7}$

\section{O SENTIDO DA VIDA E O PAPEL DO DIREITO}

A linha de verticalidade e transcendência que persegue o ser humano na sua vereda à dignidade exorta aos valores, inicialmente os que dão sentido a corporeidade, rematados por paixões, alhures, pelos clássicos, onde o prazer é o afeto e o estético na relação sujeito e sentido; mas não se esgota no útil que espolca da matéria, tampouco, conforma-se com o sentido de uma existencialidade mínima, cuja característica está em avaliar o vital, expandindo-se no que há de permanente e imperecível, o ético e o verdadeiro, patamar a conferir a felicidade (ARISTÓTELES, 1982, p. 288-289, 1100a).

\footnotetext{
${ }^{7}$ Sobre os efeitos hermenêuticos da interpretação constitucional, convém registrar obra de fôlego de Anna Paula de Barcelos, onde sublinha a eficácia positiva ou simétrica, e a eficácia negativa, decompondo-a em interpretativa e não retrocessiva dos direitos sociais.
} 
Em vida, já o dizia HEIDEGGER (2005), na concepção de seu existencialismo, as relações do sujeito com as significações do ser-aí, tornam-lhe um ser-para, dando-lhe dimensão ontológica, pelo que as faculdades cognitivas atraem a infinitude de valores tecendo o ser do humano no seu existir, e uma angústia existencial tende a ser aplacada no ato de conhecer e inteligir. Como se a felicidade dependesse dessa transcendência da consciência ao ser-aí da mundanidade.

Menos metafísico é FREUD (2010, p. 63-64), narrando os aspectos superficiais, e, portanto, puramente psíquicos da cognição humana ao esclarecer sobre uma phisys que o leva a agir, designando-a de princípio do prazer. Na visão da psicanálise esse prazer não se preenche, é sempre uma lacuna a exortar o desejo, como se o desejo de desejar fosse tateando às cegas, pela via da ação, a vida humana. De toda maneira, este prazer está associado à vida humana, como passa a considerar detidamente:

Aquilo que em seu sentido mais estrito é chamado de felicidade surge antes da súbita satisfação de necessidades represadas em alto grau e, segundo sua natureza, é possível apenas como fenômeno episódico. Toda permanência de uma situação anelada pelo princípio do prazer fornece apenas uma sensação tépida de bem-estar; somos feitos de tal modo que apenas podemos gozar intensamente o contraste e somente muito pouco o estado. Dessa forma, nossas possibilidades de felicidade já são limitadas pela nossa constituição. Muito menores são os obstáculos para experimentar a infelicidade. $O$ sofrimento ameaça de três lados: a partir do próprio corpo, que, destinado à ruína e à dissolução, também não pode prescindir da dor e do medo como sinais de alarme; a partir do mundo externo, que pode se abater sobre nós com forças superiores, implacáveis e destrutivas, e, por fim, das relações com os outros seres humanos. O sofrimento que provém desta última fonte talvez seja sentido de modo mais doloroso que qualquer outro; tendemos a considerá-lo como um ingrediente de certo modo supérfluo, embora não seja menos fatalmente inevitável do que o sofrimento oriundo de outras fontes.

Enfrentada a teoria freudiana da psicanálise, afeiçoa-se ao desejo a ação para atingir-se o prazer, a despeito de interceptar o exame do agir no plano psicológico, relegando a esfera do ético e do metafísico por seguir as ensinanças nietzschianas de que no recôndito do ser habita um Dionísio que impede a situação derradeira de desespero.

Mais otimistas são as contribuições de JUNG (1980, capítulo IV):

A energia psicológica tem o capricho de querer satisfazer suas próprias exigências. Por maior que seja a quantidade de energia existente, não podemos aproveitá-la enquanto não conseguirmos estabelecer um fluxo.

O problema do fluxo é uma questão eminentemente prática que se coloca na maioria das análises. Por exemplo, no caso propício de haver um encaminhamento da energia disponível, a chamada libido, para um objeto razoável, a nossa tendência é acreditar que a transformação foi operada por um esforço consciente da vontade. Mas nos enganamos redondamente. Nem com 
o maior esforço do mundo conseguiríamos isso, se já não houvesse simultaneamente um fluxo natural no mesmo sentido. A importância do fluxo é constatada quando, apesar dos mais desesperados esforços e de o objeto escolhido e a forma desejada serem os mais convincentes e sensatos possíveis, não se consegue operar a transformação, produzindo apenas uma nova repressão.

JUNG (1980, capítulo IV) vai esclarecer, ainda, o seu conceito de libido como energia psíquica, ou "o mesmo que intensidade energética de conteúdos psíquicos."

A busca da felicidade é tema que tem ocupado os filósofos desde há muito.

Para AGOSTINHO (2014, capítulo III, parágrafo 21, in fine), a felicidade consiste em ter Deus favorável a si, e Deus favorece a quem O procura, o que faz com que a procura em si já seja um encontro do indivíduo com Deus, já que a própria procura atrai o favor divino: “quem já encontrou Deus e tem-n'O favorável, é feliz; quem procura Deus, tem-n'O favorável mas ainda não é feliz; pelo contrário, quem se afasta de Deus, por vícios e pecados, não só não é feliz como não vive com o favor de Deus".

O que se mostra tangível e histórico, portanto, é a dimensão do ético, enquanto estágio intermediário entre o puramente egoico, e o misterioso místico.

No plano do bem comum, ou seja, no sítio ético, em que as relações humanas exigem dos consortes respeito recíproco porque são pessoas, há uma transcendência horizontal catalogada em MONDIN (2005), que conduz ao permanente e duradouro, estende felicidade, e imanta de sentido a ação.

Por outro lado, em concretização mundana da dignidade, a pessoa humana ter pelo menos a possibilidade de buscar a felicidade na relação de emprego na qual se insere é algo sem o que não se cogita que possa ter seu fluxo psicológico de encaminhamento energético com destino a um objeto (ou seja, motivação) efetivamente concretizado.

Pois bem, o modus vivendi do homo faber o impele ao trabalho para produção, com significado cultural ímpar, não somente garantindo-lhe fonte de sustentação própria e familiar, o mínimo existencial sem o qual padece, razão por que a primeira diretriz da Encíclica Rerum Novarum foi a do salário vital, sugerindo-se paga à energia de trabalho que pudesse garantir a integridade físico-psíquica do laborista, independente da sua produtividade. Eis a solidez de existência e preservação da natureza humana.

MASLOW (s/d, p. 28) verbera que é preferível expressar e encorajar a natureza humana a suprimi-la e destaca sintomaticamente que uma natureza humana que guie e ancore o sujeito é reflexo de crescimento "sadio, fecundo e feliz". Se, pelo contrário, esse "núcleo essencial da pessoa for negado ou suprimido, ela adoece, por vezes de maneira óbvia, outras 
vezes de uma forma sutil, às vezes imediatamente, algumas vezes mais tarde."

Portanto, o exercício do labor há se ser caucionado por medidas ético-jurídicas que permitam esse desabrochar da natureza humana, desaguando em deveres limitantes ao Estado no sentido de reconhecer a legitimidade de qualquer trabalho lícito, o que já se pontua no art. $5^{\circ}$, XIII, da CF, mas também de fixar-se limites e garantias horizontais, tarefa cabente ao direito do trabalho, bastando a leitura do caput do art. $7^{\circ}$, da $\mathrm{CF}$, para se escrutar os deveres do tomador em relação ao laborista, retratando, ademais, que estes abordes mínimos não esgotam a proteção às relações de trabalho quando deveres mais favoráveis forem estendidos aos laboristas, sejam do plano individual ou do coletivo (princípio da autonomia coletiva de que cogita o art. $7^{\circ}, \mathrm{XXVI}$, da CF). E, ainda, uma imposição de natureza afirmativa dos grupos intermediários, como sindicatos, associações, e o Estado, como grupo melhor aparatado a interceder em prol da classe trabalhadora.

O sentido de vida, e sua eminente dignidade, portanto exorta um aporte à integridade físico-psíquica do trabalhador, sem bastar à metafísica humana que, como projeto a-fazer, implica em espaço ético dentro do qual as potencialidades da alma transcendam, e isso há de ser viabilizado no ambiente de trabalho.

\section{O GARANTISMO TRABALHISTA E O SEU ABRANDAMENTO PELO FENÔMENO DA FLEXIBILIZAÇÃO}

Alhures já aduzia NASCIMENTO (1997, p. 121-122) ao garantismo trabalhista que enxerta a Constituição Federal, fixando impediência à tentativa de ajuste contratual flexível, porquanto uma vontade social imanta as relações empregatícias, como se nota de seu escólio:

[...] que supõe uma concepção de direito do trabalho inflexível e indisponível quanto a determinados direitos, que, por serem de ordem pública social e fundamentais para o trabalhador, são assegurados, pela legislação, como mínimos e inderrogáveis, garantia essa da qual não são cercados os demais direitos acima desse patamar imodificável.

\footnotetext{
${ }^{8} \mathrm{O}$ autor enumera ali pressupostos básicos de seu ponto de vista acerca do que considera consistir uma "psicologia da saúde".
} 
Não descura o mesmo autor (2011, p. 117-118) de certa tendência atual no sentido de que o protecionismo implacável pudesse ceder em algumas hipóteses, dadas as necessidades sócio-econômicas próprias de uma sociedade dinâmica, considerando:

É importante para o País o funcionamento das empresas para produzir bens e prestar serviços à sociedade e para abrir vagas para os trabalhadores. O direito do trabalho é complexo. Tem como principal função a tutela do trabalhador mas não pode ignorar as necessidades substanciais das empresas. Esse atendimento é necessário. As empresas precisam crescer e impulsionar a economia para dar maior número possível de vagas de trabalho.

Esse dirigismo trabalhista cedeu parcialmente, aos olhos do saudoso mestre (2011, p. 119), diante de três paradigmas: "as crises econômicas, a redução de custos como meio de enfrentamento da competição empresarial e o avanço tecnológico que permite maior produção com menor número de empregados."

Outrossim, lavram os doutrinadores do trabalho lições uniformes de que proteções à personalidade do laborista não poderão ser expungidas do contrato, até porque a legislação constitucional do trabalho foi guindada ao plano de cláusula pétrea, e nem mesmo o poder reformador haveria de cingir os bens originariamente consagrados ao empregado. Evidente que, nos espaços fixados pela própria Constituição, a saber, a redução de salários, a compensação de jornada e os turnos ininterruptos de revezamento, mediante interferência sindical, admite-se a flexibilização trabalhista, sem que isso signifique a precarização do emprego (ZENNI \& OLIVEIRA, 2008, p. 82 e seguintes).

Resta escrutar se a terceirização, enquanto técnica de flexibilização trabalhista, pode ser admitida pelo sistema jurídico pátrio, mormente nas condições em que está elaborado pelo Projeto Lei 4.330/2004, já aprovado pela Câmara dos Deputados.

\section{A TERCEIRIZAÇÃO NO DIREITO DO TRABALHO BRASILEIRO}

A rigor, o direito brasileiro admite a terceirização, desde que não suscite a ideia de precarização das relações empregatícias, porquanto nesse modelo estaria a ofender as barreiras postas à livre iniciativa.

A terceirização é, com efeito, uma forma de flexibilização do direito do trabalho, porque perverte a ordem de relação presente no art. $2^{\circ}$, da CLT, acometendo a terceiro os requisitos do patrão, tais como a contratação, remuneração, poder diretivo e os riscos da atividade, a despeito de o laborista render a energia laborativa ao tomador. Nesse sentido é uma flexibilização horizontal, dando-se no processo de contratação da mão-de-obra obreira. 
O fenômeno passa a ser vislumbrado no direito brasileiro na década de oitenta, agudizando-se nos anos noventa, entrementes a terceirização exsurge pela implantação do modelo toyotista de produção, em que a esteira e o cadenciamento linear são substituídos pela descentralização produtiva e a simultaneidade dos processos, designados de just-in-time, pelo que partes do setor de produção são deslocados, migrando à rede produtiva.

O capitalismo tardio tenciona à máxima eficiência do sistema e a forma expedita, célere e de baixo custo estaria na técnica da terceirização da produção. Aliás, os doutrinadores apontam como efeitos da terceirização a economia de passivo no treinamento e aperfeiçoamento da mão de obra, ainda a redução nos investimentos com máquinas, equipamentos e utensílios (MARTINS, 2009, p. 11).

Já os juristas indicam um enfraquecimento vertiginoso na atuação sindical, dada a fragmentação das categorias em face à classificação da representatividade sindical no direito brasileiro. A diluição da categoria profissional declina o processo representativo e fragiliza a negociação, a fortiori o exercício da greve.

Teoricamente a terceirização é procedimento flexibilizatório implicitamente admitido no texto constitucional, porquanto a livre iniciativa pressupõe que o empregador articule o processo estrutural para captação do lucro, dirigindo o negócio como lhe aprouver, desde que observados os limites consubstanciados no art. 170, da CF.

Maurício Godinho Delgado aponta a legalidade da terceirização e seu surgimento no direito brasileiro a partir do Decreto-Lei 200/67 e Lei 5.645/70, a propósito do recrutamento de labuta pela Administração Pública, no âmbito das atividades executivas ou operacionais relacionadas à esfera pública (DELGADO, 2014, p. 453, 455 e seguintes). ${ }^{9}$

A precariedade do direito positivo fez eclodir o entendimento sumulado no Enunciado 256, do TST, limitando as terceirizações àquelas provenientes de expressa disposição legal, embora não expansiva às terceirizações no setor público.

\footnotetext{
${ }^{9} \mathrm{O}$ autor deixa claro que tais hipóteses evidentes de terceirização, mais modernas em relação à edição da CLT, somam-se àquelas mais discretas já previstas no texto original consolidado, da empreitada e da subempreitada, incluída a pequena empreitada.
} 
Após o surgimento da terceirização prevista pela legislação na esfera de serviços de apoio em vigilância bancária e nas limpezas e zeladorias, o TST encorpou em Súmula o expediente da terceirização no tegumento do Enunciado n. 331, admitindo, em síntese, que somente nas atividades meio o procedimento da flexibilização horizontal é legítimo, e, ainda assim, atrai a responsabilidade subsidiária do tomador do trabalho, excepcionando-se a Administração Pública na licitação, cuja responsabilidade recairá ao Ente Público se for comprovada a negligência na averiguação do repasse de valores nos pagamentos dos licitados a seus laboristas.

A terceirização nas atividades fim conduz ao reconhecimento direto da relação empregatícia com o tomador do trabalho, à guisa das consequências lançadas à terceirização por interposta pessoa, como, ainda, passou a ser tratada com deferência a atividade inserida em zona de cizânia, em que não se reconhece com absoluta limpidez ser ou não atividade fim, no que se passa a admitir a terceirização desde que não haja subordinação e pessoalidade diretas entre tomador e laborista terceirizado.

A responsabilidade supletiva imputada ao tomador consiste no "dever de fiscalizar o cumprimento das obrigações trabalhistas da empresa escolhida. É o desdobramento da responsabilidade civil quanto às relações do trabalho, por meio da culpa in eligendo $e$ in vigilando. Deve solicitar, mensalmente, a comprovação quanto aos recolhimentos previdenciários, fiscais e trabalhistas" (JORGE NETO \& CAVALCANTE, 2009, p. 99).

Entrementes, já na vigência da Súmula 331, do TST, a essência da terceirização denuncia técnica de precarização das relações de emprego, conquanto advenha de um sistema de otimização engendrado pelo capitalismo onde o empregador angaria aumento produtivo e redução de custos pela via da contratação de mão de obra. Obviamente que a fragmentação sindical conduz à redução de salários e benefícios coletivamente conquistados (FRANCO \& DRUCK, 2007, p. 65).

O próprio discurso empresarial endossa a precarização nas relações de trabalho, porquanto o vínculo empregatício terceirizado passa a ser a retórica a justificar o preço avultante e impediente à competitividade, próprio de uma relação tradicional preconizada pelo art. $2^{\circ}$, da CLT.

Noutra senda, são diversos os expedientes de fraude no âmbito das terceirizações, exemplificando-se com as cooperativas de trabalho, hodiernamente regidas pela Lei 12.690, de 19 de julho de 2012, sendo que as limitações naturais encontradas pelo Ministério do Trabalho e Emprego e pelo Ministério Púbico do Trabalho induzem ao praxismo do subterfúgio. 
Não se descura que o laborista terceirizado que foi vítima de uma fraude sofre aguda discriminação na forma de tratamento, tema que ensejaria reflexão no campo dos direitos da personalidade.

\section{AS PRINCIPAIS ALTERAÇÕES DA TERCEIRIZAÇÃO NO PROJETO DE LEI N. 4.330/04}

De plano os doutrinadores maculam o projeto por vislumbrarem nele grosseira inconstitucionalidade (AMORIM, 2015).

Se alhures a terceirização ultra legis redundava em macroscópica fraude à luz da interpretação do TST, ressalvando-se o expediente a partir do contrato temporário de trabalho (Lei 6.019/74), nos serviços de vigilância (Lei n. 7.102/1983), e asseio, conservação e limpeza, conforme exortado na Súmula 256, do TST, a partir de uma realidade sócio- econômica implantada pelo modelo toyotista de produção, sucederam-se práticas flexibilizatórias que desaguaram na admissibilidade da terceirização em qualquer atividade meio (Súmula 331, do TST).

Ocorre que a terceirização redunda em inequívoca precariedade do trabalho, bastando notar que há redução salarial, periclitação no meio ambiente de labor, com dados seguros de acidentes laborais com redução de capacidade laborativa, sem embargo de que há uma instabilidade na manutenção do trabalho em contraste com o princípio da continuidade, base do vínculo laboral, discriminação no tratamento dos terceirizados, além de toda a danosidade ao direito coletivo pela fragilização das categorias.

A possibilidade de terceirização dar-se-ia em todas as atividades fins, bastando leitura atenta dos arts. $2^{\circ}$ e $3^{\circ}$, do projeto em testilha.

Releve-se o tegumento dos artigos 15 e $17 \S 5^{\circ}$ ao preverem a responsabilidade solidária entre contratante e contratada pelo inadimplemento de obrigações previstas nos incisos I a VI do art. 16 e por contribuições previdenciárias.

Ainda assim, no escólio de AMORIM (2015) há "afronta diretamente à Constituição da República, por violar o necessário equilíbrio entre os princípios constitucionais conflitantes, privilegiando os interesses expansivos do capital em detrimento do sistema constitucional de proteção aos direitos fundamentais dos trabalhadores”, valorizando sobremodo a livre iniciativa, alargando a "liberdade de contratação de serviços para além do permissivo constitucional, já que submete a sacrifício desproporcional os princípios do valor social do trabalho e da função social da propriedade". 
Mas o tema da terceirização nas atividades fins do tomador já era debatido na doutrina em 2005, tanto que Augusto Cezar Ferreira de Baraúna criticava a posição dos Tribunais do Trabalho salientando que "a jurisprudência não deve restringir a terceirização aos estágios inicial e intermediário, com a inclusão do avançado, desde que a terceirização não seja fraudulenta."(apud JORGE NETO \& CAVALCANTE, 2009, p. 98))

Ocorre que a terceirização nas atividades fins representa, indubitavelmente, um retrocesso à proteção aos direitos personalíssimos, ignorando o principal elemento da dignidade da pessoa enquanto valor supremo, porque derroga a inexorável presença da igualdade no mundo do trabalho e derriça o direito coletivo do trabalho.

Essas objurgações não passaram despercebidas por BARROS (2011, p. 358):

Tanto a Justiça do Trabalho como o Ministério Público não tem medido esforços no combate à terceirização de serviços ligados à atividade-fim da empresa fora dos limites traçados pelo Enunciado no 331 do TST. Entre os malefícios da terceirização em atividade-fim das empresas encontram-se a violação ao princípio da isonomia, a impossibilidade de acesso ao quadro de carreira da empresa usuária dos serviços terceirizados, além do esfacelamento da categoria profissional.

Registre-se que o projeto de lei propõe a plenitude da contratação terceirizada nas esferas privadas, pulverizando-se em todos os setores da economia e atingindo qualquer profissão, atividades e funções, bastando que a empresa de terceirização seja especializada.

Esse panorama trazido à colação pelo projeto implica em revogação dos quadros instalados no direito brasileiro a propósito da terceirização, atualmente admitida nos serviços de vigilância, limpeza, asseio e conservação, limpeza, os demais serviços ligados às atividades de apoio do tomador, sem que se mantenha subordinação e pessoalidade diretas, e para os que assim compreendem no quadro classificatório, o trabalho temporário.

A terceirização indiscriminada desembocará na inevitável migração dos laboristas permanentes e ancorados nos quadros funcionais dos tomadores às labutas por terceirização, enfraquecendo sensivelmente a garantia de direitos, mormente pela cisão das categorias profissionais e a palidez das negociações coletivas. O próprio sentido de categoria se esvaziaria, cambiando os laboristas em prestadores de serviços e os desqualificando como profissionais categorizados, como, por exemplo, bancários, professores, comerciários.

Se já se observa no âmago da terceirização dação de direitos trabalhistas de menor envergadura em cotejo com os direitos previstos aos empregados diretamente contratados pelo tomador empregador, indubitável que a terceirização amplificada redundará em minorações salariais, cláusulas simplistas, e a existencialidade mínima consolidada pelo direito do 
trabalho será afetada portentosamente, qualificativo que não se compraz com o princípio do valor social do trabalho.

Nem se releguem os aspectos previdenciários subjacentes à terceirização, que também serão precarizados, não só em virtude de as rendas serem aviltadas e, consequentemente, interferirem nas receitas previdenciárias, como, ainda, causará um curto-circuito no Fundo de Garantia do Tempo de Serviço (FGTS) e no Sistema Único de Saúde (SUS), dadas as perdas de receitas parafiscais e o número inigualável de acidentes de trabalho e doenças profissionais vislumbrados nas relações terceirizadas, cujas estatísticas já são alarmantes.

Tratar o laborista como dado, estatística, ou número no cálculo do engajamento sócioeconômico é, naturalmente, relativizar valor absoluto da dignidade da pessoa humana, com o que o direito não pode convolar.

\section{A NECESSIDADE DE UMA ÉTICA ALTRUÍSTA NA ELABORAÇÃO E NA APLICAÇÃO DA LEGISLAÇÃO TRABALHISTA E DO DIREITO DO TRABALHO}

Segundo SARMENTO (2010, p. 332-333), tanto o Direito quanto a Política "são praticados por homens que bem andarão ao adotar uma ética altruísta, cada indivíduo voltado não somente para si próprio, mas para todos e cada um dos demais integrantes da comunidade, valorizando-nos todos uns aos outros como pessoas humanas que somos."

O trabalho como direito social exige a realização do bem comum, como imperativo ético de relações intersubjetivas de distribuições justas dos valores, confere ao laborista a manutenção própria e familiar, fomentando um clima de estabilidade com pulverização ao seio comunitário, sem prejuízo de que qualquer espaço comum de realização ética é, também, uma oportunidade para transcendência horizontal, seja no plano da verdade, da justiça ou da beleza, eis o sentido permanente que requesta a dignidade da pessoa.

Se as relações trabalhistas passam pelo procedimento de precarização, com garantias menos expressivas, diluição de classes e representatividade, e tudo em nome da pujança da livre iniciativa, a contrapartida da responsabilidade social da propriedade, o denodo à valorização social do trabalho e, enfim, a dignidade do empregado, não passarão de postulados constitucionais sem eco, menos ainda ampla efetividade, frustrando os objetivos da teoria dos direitos fundamentais.

Assim, mesmo com o abrandamento do garantismo trabalhista, mencionado por Amauri Mascaro Nascimento conforme acima se referiu, aspectos fundamentais da proteção 
da dignidade da pessoa humana hão de ser preservados pelo direito do trabalho, como os mencionados por último.

Conforme se demonstrou, tais aspectos fundamentais da proteção da dignidade da pessoa humana não são preservados pelo Projeto de Lei n. 4.330/2004, aprovado na Câmara dos Deputados e em trâmite no Senado Federal quando da elaboração do presente artigo.

Por outro lado, a proteção da dignidade da pessoa humana do trabalhador há de ser consagrada pela atuação das instituições trabalhistas do país, cada qual com características e atribuições próprias, como adiante será visto.

Passemos a ver, agora, a atuação da Auditoria-Fiscal do Trabalho, em particular, e das demais instituições trabalhistas brasileiras, na realização concreta da flexibilização trabalhista que se considera aceitável que exista no país.

\section{A ATUAÇÃO DAS INSTITUIÇÕES TRABALHISTAS BRASILEIRAS EM GERAL, E EM PARTICULAR DA AUDITORIA-FISCAL DO TRABALHO, NA REALIZAÇÃO CONCRETA DA FLEXIBILIZAÇÃO TRABALHISTA QUE SE CONSIDERA JUSTO QUE EXISTA NO PAÍS}

Como responsável pela implementação e execução das políticas públicas federais relativas ao trabalho, o Ministério do Trabalho e Emprego (MTE) age por meio dos servidores que detêm as correspondentes competências legais.

As tarefas de fiscalização do trabalho são desempenhadas por Auditores-Fiscais do Trabalho, que detêm competência legal para tanto (BRASIL, 2002) ${ }^{10}$.

A atividade da fiscalização do trabalho será tratada aqui ao lado das realizadas por outras instituições que criam e aplicam a legislação trabalhista e o Direito do Trabalho no Brasil, como o Poder Legislativo, o Poder Judiciário, e pelos ramos das funções essenciais à Justiça com atuação trabalhista, como a Advocacia, inclusive a pública, e o Ministério Público do Trabalho.

Todas as mencionadas instituições detêm protagonismo na elaboração e/ou aplicação da legislação e do direito do trabalho no Brasil. Assim sendo, também o são quanto à flexibilização trabalhista que se considera justo que exista no país, à luz dos valores constitucionais do trabalho, da livre iniciativa, da proteção do pleno emprego e da dignidade da pessoa humana, antes já vistos.

\footnotetext{
10 Art. 11 da Lei n.10.593, de 6 de dezembro de 2002 e art. 18 do Regulamento da Inspeção do Trabalho, aprovado pelo Decreto n. 4.552, de 27 de dezembro de 2002.
} 
A competência para o trato de temas pertinentes ao trabalho é, no Brasil, da União Federal (Constituição, art. 22, I). A elaboração da legislação é realizada segundo os ditames do processo legislativo federal, que distribui competências entre o Presidente da República (artigos 76 e 84) e o Congresso Nacional (art. 48), suas duas Casas (Câmara dos Deputados e Senado Federal), membros (Deputados e Senadores) e Comissões, na forma dos respectivos regimentos internos.

A aplicação contenciosa da legislação trabalhista e do direito do trabalho, bem como o desenvolvimento da jurisprudência trabalhista que consiste em fonte do direito do trabalho incumbe ao Poder Judiciário da União, especificamente à Justiça do Trabalho e seus órgãos (TST, TRTs e Juízes do Trabalho), conforme previsão do artigo 92, inciso IV, e artigos 111 e seguintes da Constituição Federal.

Na seara administrativa, conforme características próprias da Administração Pública, em especial o exercício do poder de polícia, a aplicação da legislação trabalhista e do direito do trabalho incumbe ao Ministério do Trabalho e Emprego (Constituição, art. 84, II). Em especial, a fiscalização do trabalho, à cuja realização o Brasil se obrigou por instrumentos internacionais como a Convenção n. 81 da OIT, e constitucionalmente (art. 21, XXIV), incumbe à Auditoria-Fiscal do Trabalho. Tal atividade, além da expressa previsão constitucional, tem sua organização prevista por leis e regulamentos, como adiante será visto.

São instituições trabalhistas também atuantes no país os ramos das funções essenciais à Justiça que têm atuação trabalhista, como a Advocacia (Constituição, art. 133), inclusive a pública (artigos 131 e 132), e o Ministério Público do Trabalho (MPT, artigos 127 e 128, I, b).

\subsection{Aspectos Históricos da Fiscalização do Trabalho}

As fontes materiais da criação da Fiscalização do Trabalho estão ligadas ao próprio surgimento do Direito do Trabalho.

NASCIMENTO (1997, p. 9-10), em parte intitulada "A indignidade das condições de trabalho subordinado", descreve as condições de trabalho no início da Revolução Industrial:

\footnotetext{
A imposição de condições de trabalho pelo empregador, a exigência de excessivas jornadas de trabalho, a exploração das mulheres e menores, que constituíam mão-deobra mais barata, os acidentes ocorridos com os trabalhadores no desempenho das suas atividades e a insegurança quanto ao futuro e aos momentos nos quais fisicamente não tivessem condições de trabalhar foram as constantes da nova era no meio proletário, às quais podem-se acrescentar também os baixos salários.
} 
A criação da inspeção do trabalho se deu em tal contexto histórico e social. Em 1839, a Câmara dos Comuns da Grã-Bretanha publicou volume contendo relatórios dos quatro Factory Inspectors então existentes, "para os efeitos das disposições educacionais" do Factory Act (GRÃ-BRETANHA, 1839).

Conforme lição de RENZO (2007, p. 30), a Conferência de Berlim de 1890 recomendou a formação de quadros de inspetores especializados, pagos pelo governo.

A inspeção do trabalho é reconhecida hoje como um instrumento chave para a promoção do desenvolvimento com justiça social (CASALE \& SIVANANTHIRAN, 2011, p.

51 e seguintes).

É também crucial para a compreensão da evolução do Direito e da Inspeção do Trabalho no Século XX a análise das condições de vida na Europa no pós-Primeira Guerra Mundial, que vieram a se constituir em um dos maiores causadores da Segunda Guerra Mundial. Muitos historiadores chegam a considerar ambas como uma só guerra, com um hiato de paz entre um e outro momento.

O péssimo resultado do Tratado de Versalhes foi o de pavimentar o caminho para a Segunda Guerra Mundial. Isso aconteceu em decorrência da imposição, pelos vencedores, de pesadas reparações de guerra à Alemanha, considerada responsável pela deflagração da Primeira Guerra Mundial e dos prejuízos dela decorrentes (NICOLSON, 2014, a partir do $3^{\circ}$ parágrafo do capítulo 8 do Livro I).

Com efeito, a depauperação da sociedade alemã causada pela aplicação de suas disposições é causa direta da Segunda Guerra Mundial, já que levou ao surgimento e à ascensão do nazismo.

Por outro lado, um bom resultado do Tratado foi a criação da Organização Internacional do Trabalho (OIT), em razão do reconhecimento internacional da importância da organização do trabalho para a manutenção da paz entre as nações.

A tal respeito, RODGERS, LEE, SWEPSTON \& VAN DAELE (2009, p. 2-3) afirmam que dois detonadores provocaram a criação da OIT: a guerra e a revolução, já que uma característica do século XX em relação aos séculos anteriores foi o de que a atividade humana parecia se estruturar intensamente em torno da guerra e do trabalho, em parte porque tanto um quanto outro começaram a adquirir dimensão mundial.

Conforme evidenciam tais autores, foi em decorrência das marcas obscuras deixadas pela Primeira Guerra Mundial que os líderes políticos internacionais se abriram a uma mudança fundamental tanto na política como na economia e na sociedade em geral, inclusive 
com a criação de instituições de caráter internacional, como a OIT, que pudessem unir a todos os países em um esforço comum. ${ }^{11}$

Foi objetivo da criação da OIT, constante do preâmbulo da sua Constituição, o de “estabelecer a paz universal, que não pode ser fundada senão sobre a base da justiça social”.

Base fática da criação da OIT, constante do mesmo preâmbulo, é a de que: "existem condições de trabalho que implicam para um grande número de pessoas em injustiça, miséria e privações" e "a não adoção por uma nação qualquer de um regime de trabalho realmente humanitário é um obstáculo aos esforços dos demais, desejosos de melhorar a sorte dos trabalhadores nos seus próprios países". ${ }^{2}$

Sobre a inspeção do trabalho, a OIT aprovou a de n. 81, de 1947, que trata da inspeção do trabalho.

Já no Brasil, o primeiro diploma jurídico a tratar da inspeção do trabalho foi o Decreto $\mathrm{n}^{\mathrm{o}}$ 1.313, de 17 de Janeiro de 1891, que estabelece, conforme a ortografia da época, "providencias para regularisar o trabalho dos menores empregados nas fabricas da Capital Federal."

Por meio do mencionado decreto, o Chefe do Governo Provisório instituía, já pelo art. $1^{\circ}$, a "fiscalização permanente de todos os estabelecimentos fabris em que trabalharem menores, a qual ficará a cargo de um inspector geral, immediatamente subordinado ao Ministro do Interior". A tal inspetor era garantido, desde a época, o "direito de livre entrada em todos os estabelecimentos fabris, officinas, laboratorios e depositos de manufacturas da Capital Federal", no que vinha a ser o precursor do livre acesso que hoje os agentes de inspeção do trabalho têm, por força do art. 630, $\S 3^{\circ}$, da Consolidação das Leis do Trabalho.

O Brasil ratificou a Convenção n. 81 da OIT em 1957, denunciou-a em 1971 e rerratificou-a em 1987.

\footnotetext{
${ }^{11}$ Na p. ix há a importante menção de Juan Somavia, advogado e diplomata chileno que então ocupava o cargo de Diretor-Geral da organização, ao fato de que a OIT recebeu o Prêmio Nobel da Paz de 1969. O livro deu início a um projeto denominado "Centenário", para comemorar o 100 anos da organização, que serão completados em 2019.

${ }^{12}$ A Constituição da OIT, a Declaração de Filadélfia, a Declaração da OIT Relativa aos Princípios e Direitos Fundamentais no Trabalho e o Regulamento da Conferência Internacional do Trabalho são, considerados como os documentos fundamentais da organização.
} 
A rerratificação foi operada por meio do Decreto $n^{\circ} 95.461$, de 11 de dezembro de 1987. Tal diploma revogou o Decreto $\mathrm{n}^{\circ}$ 68.796, de 23 de junho de 1971, e revigorou o Decreto $n^{\circ} 41.721$, de 25 de junho de 1957, concernentes à Convenção $n^{\circ}$ 81, da Organização Internacional do Trabalho.

\title{
9.2 Natureza jurídica da atividade de inspeção do trabalho
}

No Brasil a inspeção do trabalho é exercida por servidores públicos federais que exercem o cargo de Auditor-Fiscal do Trabalho.

As competências legais e regulamentares do mencionado cargo são estabelecidas pela Lei n. 10.593, de 6 de dezembro de 2002, e pelo art. 18 do Regulamento da Inspeção do Trabalho, aprovado pelo Decreto n. 4.552, de 27 de dezembro de 2002.

As atividades de exercício de tal cargo são disciplinadas pelo direito administrativo do trabalho.

Tal ramo não autônomo do direito é formado por normas, princípios e jurisprudência, tanto judicial quanto administrativa, acerca do funcionamento do ramo da Administração Pública executiva voltado à inspeção do cumprimento da legislação trabalhista, em conformidade com o direito do trabalho.

Releva, em tal atividade, o tema da polícia administrativa, sobre cujo fundamento manifesta-se o administrativista GASPARINI (2003, p. 120):

\begin{abstract}
O fundamento da atribuição de polícia administrativa está centrado num vínculo geral. existente entre a Administração Pública e os administrados. que autoriza o condicionamento do uso, gozo e disposição da propriedade e do exercício da liberdade em benefício do interesse público ou social. Alguns autores chamam-no de supremacia geral da Administração Pública em relação aos administrados. Assim. o exercício da liberdade e o uso, gozo e disposição da propriedade estão sob a égide dessa supremacia. e por essa razão podem ser condicionados ao bem-estar público ou social. É um princípio inexpresso no ordenamento jurídico.
\end{abstract}

Assim, temos que, sem sacrifício dos direitos de liberdade e de propriedade das partes dos contratos de trabalho (e em especial, do empregador), o exercício de tais direitos é condicionado pelas normas trabalhistas em benefício do interesse público de realização da justiça social e de efetivação do princípio constitucional da dignidade da pessoa humana.

Tal princípio, como acima já foi visto, protege ou ambas as partes do contrato de trabalho ou, no caso dos empregadores pessoas jurídicas, as pessoas físicas que as representam.

Mesmo que, conforme a doutrina acima transcrita, o poder de polícia seja inexpresso no ordenamento jurídico, é verdade que existem normas jurídicas trabalhistas que expressamente determinam às autoridades de inspeção o dever de agir (como o art. 628, 
caput, da CLT) e o embargo ou interdição impostos em decorrente de grave e iminente risco à vida ou à saúde dos trabalhadores, conforme a NR-3 e item 28.2.1 da NR-28, estabelecidas pelo Ministro do Trabalho e Emprego por força do disposto no art. 200 da CLT.

Menciona-se que recentemente, por força de decisão judicial na Ação de Mandado de Segurança ajuizada pelo Ministério Público do Trabalho da $14^{\mathrm{a}}$ Região (em Rondônia), declarou-se judicialmente a competência dos Auditores-Fiscais do Trabalho para os embargos e interdições ${ }^{13}$.

Foi editada, também, a Portaria n. 1.719, de 5 de novembro de 2014, do Excelentíssimo Senhor Ministro de Estado do Trabalho e Emprego, que disciplina os procedimentos administrativos relativos aos embargos e interdições.

\section{CONCLUSÃO}

Demonstrou-se, no presente artigo, que tem sido identificada, uma necessidade de flexibilização das garantias dadas pelo Direito do Trabalho, de que é espécie a terceirização trabalhista.

A limitação que vem sendo dada à terceirização serve para dar consecução ao princípio da dignidade da pessoa humana nas relações de emprego, criando condições para que as pessoas físicas nelas envolvidas busquem a felicidade.

Também foi demonstrado que tal busca da felicidade consiste em motivação para o trabalho.

Demonstrou-se, por fim, a existência de protagonismo da Auditoria-Fiscal do Trabalho, ao lado de outras instituições trabalhistas, como a Justiça do Trabalho, o Ministério Público do Trabalho e a Advocacia trabalhista, tanto na realização da flexibilização trabalhista em geral e da terceirização em especial, quanto de sua limitação, de maneira a se manter adequada aos ditames constitucionais de proteção da dignidade da pessoa humana trabalhadora.

\footnotetext{
${ }^{13}$ É o seguinte o dispositivo do Acórdão: "Deferir a medida liminar peticionada, a fim de cassar a decisão judicial que negou a antecipação dos efeitos da tutela, nos autos do Processo 0010450-12.2013.5.14.0008, a fim de suspender os efeitos da Portaria SRTE-RO n. 66, de 22 de julho de 2013, e declarar que os auditores-fiscais do trabalho estão autorizados a ordenar a adoção de medidas de aplicação imediata, incluindo interdições e embargos, e o consequente levantamento posterior dos mesmos, quando se depararem em ação fiscal com uma situação de perigo iminente à vida, à saúde ou à segurança dos trabalhadores, não havendo necessidade da medida, para início ou manutenção da produção de seus efeitos, ser previamente autorizada ou confirmada por autoridade diversa não envolvida na ação fiscal, ressalvada exclusivamente a possibilidade de posterior recurso ao órgão superior em matéria de saúde e segurança, em Brasília”.
} 


\section{REFERÊNCIAS}

AGOSTINHO, Santo. Diálogo Sobre a Felicidade. Trad. do original latino de Mário A. Santiago de Carvalho. 2a . ed. Lisboa: Edições 70, 2014.

AMORIM, Helder Santos. O PL 4.330/2004-A e a Inconstitucionalidade da Terceirização Sem Limite. Disponível em: <http://esquerdapopularsocialista.com.br/wpcontent/uploads/2012/07/Artigo-Terceiriza\%C3\%A7\%C3\%A3o_Helder-Amorim1.pdf> Acesso em: 17 de junho de 2015.

AQUINO, Santo Tomás de. Suma de Teología. Trad. de José Martorell Capó, $4^{a}$. ed., Madri, Biblioteca de Autores Cristianos, 2001.

ARISTÓTELES, Ética Nicomaquea. In: .ARISTÓTELES, Obras. Trad. del griego, estudio preliminar, preâmbulos y notas por Francisco de P. Samaranch. Madri: Aguilar, 1982.

BARCELOS, Ana Paula de. A eficácia dos Princípios Constitucionais: O principio da dignidade da pessoa humana. $2^{\mathrm{a}}$ ed. Rio de Janeiro: Renovar, 2008.

BARROS, Alice Monteiro. Curso de Direito do Trabalho. $7^{\mathrm{a}}$. ed., revista e atualizada. São Paulo: LTR, 2011.

BELTRAMELLI NETO, Sílvio. Limites da Flexibilização dos Direitos Trabalhistas. São Paulo: LTr, 2008.

BRASIL. Lei n.10.593, de 6 de dezembro de 2002 e art. 18 do Regulamento da Inspeção do Trabalho, aprovado pelo Decreto n. 4.552, de 27 de dezembro de 2002.

BRASIL. Supremo Tribunal Federal. Decisão monocrática do Ministro Gilmar Mendes no Mandado de Injunção n. 3.437/Distrito Federal, de 12 de fevereiro de 2015, negando seguimento. Disponível na Internet em: <http://www.stf.jus.br/portal/processo/verProcessoPeca.asp?id=301006839\&tipoApp=.pdf > Acesso em: 23 de agosto de 2015.

BRASIL. Câmara dos Deputados. Projeto de Lei n. 4.330/2004. Dispõe sobre os contratos de terceirização e as relações de trabalho deles decorrentes. Disponível na Internet em: <http://www.camara.gov.br/proposicoesWeb/fichadetramitacao?idProposicao=267841> Acesso em: 14 de junho de 2015.

BRASIL. Ministério do Trabalho e Emprego. Portaria n. 1.719, de 5 de novembro de 2014, que disciplina os procedimentos relativos aos embargos e interdições. Disponível na Internet em:

<http://portal.mte.gov.br/data/files/8A7C816A48EC2EA4014A1BBA533541CE/Portaria\%20 embargo\%20interdi\%C3\%A7\%C3\%A3o\%201719_2014.pdf> Acesso em: 24 de agosto de 2015.

CARVALHO, Renan. O2 - Organizações Orgânicas - Um guia para revolucionar a gestão e liderar as equipes do século XXI. Blumenau, Nova Letra, 2012. Primeiro e segundo parágrafos do primeiro capítulo, "Dilemas do Mundo Empresarial”. Disponível em: 
$<\mathrm{http}$ ///www.organicas.org/livros/o2-organizacoes-organicas/o2-online/dilemas-mundoempresarial/> Acesso em: 27 de maio de 2014.

CASALE, Giuseppe \& SIVANANTHIRAN, Alagandram. Los Fundamentos De La Administración Del Trabajo. Ginebra, Oficina Internacional del Trabajo, 2011. Disponível em: $<$ http://www.ilo.org/global/publications/ilo-bookstore/orderonline/books/WCMS_155146/lang--es/index.htm> Acesso em: 14 de fevereiro de 2015.

DELGADO, Maurício Godinho. Curso de Direito do Trabalho. 13a . ed. São Paulo: LTr, 2014.

DUCCI, Maria Paula Dallari. Políticas Públicas, reflexões sobre o conceito jurídico. São Paulo: Saraiva, 2006.

FRANCO, Tânia \& DRUCK, Graça (org.). A Perda da Razão Social do Trabalho: Terceirização e Precarização. São Paulo: Boitempo, 2007.

FRANCISCO. Exortação Apostólica Evangelii Gaudium do Santo Padre Francisco ao Episcopado, ao Clero, às Pessoas Consagradas e aos Fiéis Leigos, sobre o Anúncio do Evangelho no Mundo Actual. Disponível em: <http://w2.vatican.va/content/francesco/pt/apost_exhortations/documents/papa-

francesco_esortazione-ap_20131124_evangelii-gaudium.html>. Acesso em: 17 de novembro de 2014.

FREUD, Sigmund. O mal-estar na cultura. Trad. de Renato Zwick. Porto Alegre: L\&PM, 2010.

GONÇALVES, Diogo da Costa. Pessoa e Direitos de Personalidade - Fundamentação Ontológica da Tutela. Coimbra: Almedina, 2008.

HEIDEGGER, Martin. Ser e Tempo. Tradução de Márcio de Sá Cavalcante Schuback. 15ª ed. Petrópolis, Vozes, 2005.

JORGE NETO, Francisco Ferreira e CAVALCANTE, Jouberto de Quadros Pessoa. Curso de Direito do Trabalho. São Paulo: Atlas, 2009.

JUNG, Carl Gustav. Psicologia do Inconsciente. Trad. de Maria Luiza Appy. Petrópolis, Vozes, 1980, capítulo IV.

LEÃO XIII. Carta Encíclica Rerum Novarum do Sumo Pontífice Papa Leão XIII a Todos os Nossos Veneráveis Irmãos, os Patriarcas Primazes, Arcebispos e Bispos do Orbe Católico, em Graça e Comunhão Com a Sé Apostólica, Sobre a Condição dos Operários. Disponível na Internet em: <http://w2.vatican.va/content/leo-xiii/pt/encyclicals/documents/hf_lxiii_enc_15051891_rerum-novarum.html> Acesso em: 17 de fevereiro de 2015.

LOCKE, John. Segundo Tratado Sobre o Governo Civil e Outros Escritos. Trad. de Magda Lopes e Marisa Lobo da Costa, 3ª . ed., Petrópolis: Vozes, 2001.

MALLET, Estêvão. Direitos da Personalidade e Direito do Trabalho, Juris Plenum Trabalhista e Previdenciária, v. 13, 2007. 
MARTINS, Sérgio Pinto. A Terceirização Trabalhista e o Direito do Trabalho, $9^{a}$. ed. rev. e ampl. São Paulo: Atlas, 2009.

MARX, Karl \& ENGELS, Friedrich. Manifesto Comunista. Trad. de Álvaro Pina. Organização e introdução de Osvaldo Coggiola. São Paulo: Boitempo, 2005.

MASLOW, Abraham H. Introdução à Psicologia do Ser. Trad. de Álvaro Cabral. Rio de Janeiro: Eldorado, s/d.

MELO, Raimundo Simão. Direito Ambiental do Trabalho e a Saúde do Trabalhador, $5^{\text {a }}$. Ed. São Paulo, LTr, 2013.

MONDIN, Battista. O Homem, Quem é Ele? Elementos de Antropologia Filosófica. Tradução de R. Leal Ferreira e M. A. S. Ferrari. São Paulo: Paulus, 2005.

NASCIMENTO, Amauri Mascaro. Curso de Direito do Trabalho, 14 ${ }^{\text {a; }}$, ed., São Paulo: Saraiva, 1997; 26 ; ed., São Paulo: Saraiva, 2011.

PINTO, Eduardo Vera-Cruz. Mudar o Direito Para Chegar à Justiça Através da Crítica ao Capitalismo. Revista da Faculdade de Direito da PUC/SP, n. 2, 2º semestre de 2014.

RENZO, Rober. Fiscalização do Trabalho. São Paulo: LTr, 2007.

SARMENTO, Daniel. Direitos Fundamentais e Relações Privadas. $2^{\mathrm{a}}$. ed. Rio de Janeiro: Lúmen Juris, 2010.

SILVA, Leda Maria Messias da. O Cumprimento da Função Social do Contrato no Tocante ao Meio Ambiente do Trabalho. Disponível na Internet em: <http://www.conpedi.org.br/manaus/arquivos/anais/bh/leda_maria_messias_da_silva.pdf $>$. Acesso em: 17 de novembro de 2014. Disponível também em: <http://doctrina.vlex.com.mx/vid/social-do-contrato-trabalho-309377166>. Acesso em: 14 de novembro de 2014.

SILVA, Leda Maria Messias da \& PEREIRA, Marice Taques. Docência (In)Digna - o meio ambiente laboral do professor e as consequências em seus direitos de personalidade. São Paulo: LTr, 2013.

SÜSSEKIND, Arnaldo, MARANHÃO, Délio, VIANNA, Segadas \&e TEIXEIRA, Lima, Instituições de Direito do Trabalho. v. I, 21 a ed., São Paulo: LTr, 2003.

ZENNI, Alessandro Severino Valler. A Crise do Direito Liberal na Pós-Modernidade. Porto Alegre: Sérgio Antonio Fabris, 2006.

ZENNI, Alessandro Severino Valler e OLIVEIRA, Cláudio Rogério Teodoro. (Re)Significação dos Princípios de Direito do Trabalho. Porto Alegre: Sergio Antonio Fabris, 2008 .

ZENNI, Alessandro S. Valler \& SILVA, Elizabet Leal da. A Dignidade do Trabalhador: Bússola aos Novos Paradigmas do Trabalho, Emprego e Incremento Harmonizador entre Capital e Trabalho.

Disponível

na

Internet

em: 
<http://www.publicadireito.com.br/conpedi/manaus/arquivos/Anais/sao_paulo/2667.pdf> Acesso em: 31 de julho de 2015.

ZENNI, Alessandro Severino Valler \& FILHO ANDREATA, Daniel Ricardo. O Direito na Perspectiva da Dignidade Humana. Porto Alegre: Sérgio Antonio Fabris, 2010. 